\title{
Epidermolytic Palmoplantar Keratoderma
}

National Cancer Institute

\section{Source}

National Cancer Institute. Epidermolytic Palmoplantar Keratoderma. NCI Thesaurus. Code C84693.

A genetic skin disorder caused by mutations in the KRT 9 gene. It is characterized by hyperkeratosis in the palms and soles resulting in abnormal thickening of the skin in these areas. 